\title{
Empowering Mobile Assisted Social E-Learning: Students' Expectations and Perceptions
}

\author{
Jenny Wang ${ }^{1, *}$, Wei-Chieh Wayne $\mathrm{Yu}^{2} \&$ Emily $\mathrm{Wu}^{1}$ \\ ${ }^{1}$ Department of Applied Foreign Languages, National Formosa University, Yuling County, Taiwan \\ ${ }^{2}$ Graduate Institute of Nusing, Chang Gung University of Science and Technology, Chiayi, Taiwan \\ *Corresponding author: National Formosa University, 64, Wen-hwa Road, Huwei Jeng, Yuling County, Taiwan \\ Tel: 886-953-676866 E-mail: wang170@yahoo.com
}

$\begin{array}{ll}\text { Received: March 29, } 2013 & \text { Accepted: April 11, } 2013 \quad \text { Online Published: April 18, } 2013 \\ \text { doi:10.5430/wje.v3n2p59 } & \text { URL: http://dx.doi.org/10.5430/wje.v3n2p59 }\end{array}$

\begin{abstract}
The aim of the present study was to empower mobile assisted social e-learning (eMASE) module that was designed based on social constructivism theory in higher education settings. This study reports findings from a group of undergraduates' expectations and perceptions of e-cooperative learning using mobile social networking apps. The eMASE module of the course was carefully designed by organizing various group activities which were emphasized to encourage social interaction and promote collaborative learning among students. The data come from two sets of questionnaires administered at the start and end of the course. The results indicated that using Web 3.0 technologies in a learning environment was effective in enhancing collaboration and promote students' learning motivation and confidence.
\end{abstract}

Keywords: mobile techs; social networking apps; cooperative learning; social constructivist

\section{Introduction}

Mobile wirelessly networked technologies are contributing to new forms of learning in this generation of learners. Innovative curriculum integrated with multimedia and technology involvement has changed the ways teachers teach and the ways students learn. As users of mobile technologies become dramatically widespread worldwide, it is more likely that they will become ubiquitous in the lives of learners (Looi et al., 2010). The increasing and ubiquitous use of Web 2.0 activities, such as social networking, wikis, and blogging, provides a viable avenue for cooperative learning proactively (Ajjan \& Hartshorne, 2008; Wang, Wang, Fang, \& Lin, 2010). Pedagogically, engaging learners in cooperative learning involving sharing their ideas and work cooperatively and helpfully to complete group projects is one of the major pathways to scaffold learning development (Effandi \& Zanaton, 2007; Johnson \& Johnson, 1994) as learning is a social activity (Chen \& Bryer, 2012; Smith \& MacGregor, 1992; Vygotsky, 1978). In other words, when working and collaborating with other peers, students become highly engaged and learn more. Thus, social media tools as known as Web 2.0 activities have been used in today's classrooms to promote collaboration between students in hoping to scaffold student's learning development (Ford, Bowden, \& Beard, 2011; Grodecka, Wild, \& Kieslinger, 2009; Koh \& Lim, 2012).

In addition, with advanced Web 3.0 service features, more importantly, learners can network and have 24/7 access to resources through a hand-held device without time and space boundaries (Borovik, 2011). Based on social constructivism, cooperative learning truly responds to the meaningful learning in this information society where people focus more on team work as communication skills are essentially important. Cooperative learning also represents a shift from a teacher-centered approach to a more student-centered learning in small groups (Bauersfeld, 1995; Effandi \& Zanaton, 2007; Kan, 2011).

\subsection{Purpose of the Study and Research Questions}

The aim of this study was to gather information about college students' perception and learning experience of the e-cooperative learning course through the mobile assisted techs in a social learning environment. The focus is (a) to discover the impact on e-cooperative learning from mobile techs, and (b) to ascertain the benefits of mobile techs in 
a social learning environment. A range of free mobile apps were downloaded and implemented in this study hoping to obtain more adequate for some learning scenarios, e.g. 1) Facebook app for collaboratively posting status updates regarding the project progress about experience exchange, tagging and sharing links to resources for reaching a group project goal; 2) LINE and WeChat apps for inquiring information and help requests and constructive feedback to peers for a project or class material and also for staying connected closely and collaboratively with peers between classes; 3) Short Message Service (most commonly known as SMS, as known as text messaging) for sending quick inquiries and short announcements of interest for a project; 4) YouTube for posting rehearsal presentation for a project and offer critical feedbacks to peers; 5) Email for sending and receiving a project documentation; and 6) Skype and Google+ Hangouts for holding a video teleconference with peers. Thus, this course integrated with the assisted mobile techs led the students into such a social learning environment, called empowering Mobile Assisted Social E-learning (eMASE) module in this study. Obviously, all these apps were interchangeable. Students selected the apps they felt best suited to their needs.

The research questions examined are:

1) What are the impacts on e-cooperative learning using eMASE module?

2) What are the students' attitudes toward learning using eMASE module?

\section{Theoretical Background}

\subsection{Use of Mobile Techs}

Portable and ubiquitous, mobile technologies such as mobile phones (e.g. iPhones, smartphones), tablets (e.g. iPods, iPads, Kindles, Nooks), and personal digital assistants (known as PDAs) are contributing to new forms of learning which are no longer confined to the classroom environment (Ally, 2009; Traxler, 2009). Mobile technology indeed offers a very helpful way to reach learning goals (Deb, 2012). Mayer (2001) declares that learning from books and from computer-based environments results in better performance compared with learning from the text-only books. Similarly, mobile technologies can be interfaced with text, voice, graphics, videos, shared workspaces, or combinations of these forms. Mobile learning is profoundly more interactive, involves more human to human cooperative and communicative interaction (Deb, 2012). MoLeNET (2007) defines mobile learning as "the exploitation of ubiquitous handheld technologies, together with wireless and mobile phone networks, to facilitate, support, enhance and extend the reach of teaching and learning." Through the mobile technologies, users not only consume information, but actively contribute and share information (Ally, 2009; Kukulska-Hulme, 2010; Traxler, 2009). The use of mobile technologies is not always necessary to educate students, but, in the right context, it can help today's educators to embrace a truly learner-centered approach to learning. Mobile technology can be used for a variety of learning activities including:

1) Mobile devices are most widely used for SMS. Learners can use SMS for project work, content delivery, or a quick question and an answer. SMSs provide more communication and collaboration with people.

2) Books or course materials can be downloaded onto mobile devices (smart phones, tablets, PDAs, laptops). Particularly at higher education level, podcasting can be used to review live lectures (Schreiber, Fukuta, \& Gordon, 2010) and to provide opportunities for students to rehearse oral presentations. Podcasts provide supplemental information to enhance traditional lectures (McGarr, 2009).

3) As a large number of smart mobile devices came onto the market, it is safe to assume that mobile devices are increasing emerging as part of daily life, particularly with university students. Educators or government investors will need to advise on the range of devices most suitable for the curriculum. Mobile devices can be used to support the learning process as relatively lighter, faster, and less expensive than PCs (Godwin-Jones, 2008).

4) Mobile technology has excellent potential for providing students with rich, real time, collaborative and conversational experiences both in and outside the classroom (Lan, Sung \& Chang, 2007). This value should be used and cared.

\subsection{Social Constructivist and Cooperative Learning}

According to Bruner (1987), learning is an activity process in which learners construct new ideas or concepts based on their existent knowledge that had been developed by experiences. The social constructivism thus emphasizes the importance of the learners rather than instructors. A variety of teaching strategies have been shifted from teacher-centered approach to a more student-centered approach working in groups (Effandi \& Zanaton, 2007). 
Learners learn best when they actively involved in the learning process through social interaction with the immediate learning environment (Vygotsky, 1978; Woo \& Reeves, 2008). They are encouraged to discover their own solutions and to try out ideas and hypotheses. The responsibility of the instructor is to facilitate the students' learning process as a facilitator not a knowledge provider (Bauersfeld, 1995; Effandi \& Zanaton, 2007; Kan, 2011; Maor, 2003) so that students can exercise their capabilities in knowledge formation (Doolittle \& Hicks, 2003).

Most social constructivism models stress the need for collaboration among learners. Cooperative learning requires students to work together in groups to complete tasks collectively toward academic goals. Results from Johnson and Johnson (1975) study reported positive outcomes from cooperative learning including increasing higher level reasoning, increasing generation of new ideas and solutions, and enhancing transferring of learning between situations. Studies (Tsay \& Brady, 2010; Wang et al., 2010) also support that cooperative learning is an active pedagogy that fosters higher academic achievement. Five essential elements identified in cooperative learning include positive interdependence, individual accountability, group processing, social skills, and face-to-face interaction (Johnson \& Johnson, 1989).

\subsection{Mobile Applications}

Social constructivism claims that learning occurs as a result of social interactions. Clearly, social media applications, such as Facebook and twitter, can be used to foster social interactions between learners (Ford et al., 2011; Grodecka et al., 2009). As Vygotsky (1978) focuses on learning as activity that takes place in a social context, Libert (2010) claims that social media applications harness the power of the crowd. As social learning does not always take place in front of a computer (Ullrich et al., 2008), it is essential that learners are able to access data whenever and wherever they want (Walton, Weller, \& Conole, 2008). As mobile technology becomes more rooted in one's life, mobile apps developed for mobile technologies are now changing the way people access information. After the popularity of the online social networking, social media apps and especially Facebook has provided learners opportunities to network, collaborate, and share resources for educational purposes. Wang, Lin, Yu, and $\mathrm{Wu}$ (2012) claim that "Facebook assists students in merging their social and academic lives" (p. 318). Facebook is a tool and platform that enhances communication and human interaction.

Indeed, hand-held devices (e. g., smart phones, PDAs, mp3 players such as iPods) provide an emerging portable and potential solution that can provide learners with adaptable and ubiquitous support for accessing data and network with one another at virtually any place and any time. Clearly, SMS and apps are the most useful and most widely used in hand-held devices. In addition, wireless communications are supporting the learner in many ways ranging from use of SMS texting to the more advanced use of apps for sharing/access information and interacting with others in other areas. Learners in this generation also use their mobile phones to listen to their course lectures, and for storage and data transfer. Examples of mobile apps along with social constructive learning also include simulation, interactive podcasting, SMS, and interactive mobile TV (Keskin \& Metcalf, 2011).

\subsection{The Most Popular Mobile Social Networking Apps in Asia}

While Facebook dominates the North America market, it was no longer the most popular mobile social networking app in many Asian countries based on downloads in July 2011 to July 2012 (Spreinsma, 2012). Spreinsma (2012) found that applications like LINE and WeChat took over the leading position of Facebook in Asia. The most popular mobile social networking apps in Asia also included Skpye, Google+, and Windows Live Messenger. In general, social networking apps were designed to encourage social networking and communicate among a group of people with a shared or common interest. These most downloaded mobile social networking apps are then briefly described and categorized into two parts as follows, for communication services and for video teleconferencing services.

\subsubsection{Communication Services}

Facebook: Facebook created by Mark Zuckerberg in 2004 is the most popular SNS in North America and the largest proportion of overall Internet traffic. Facebook provides opportunities for sharing social and emotional support, information resources and bonds with other people (Cheung, Chiu, \& Lee, 2011). In March 2012, the number of mobile active users was 490 million solely through mobile apps (Facebook 2013). However, some countries had issued access bans to Facebook, such as China, Vietnam, Iran, and Syria.

LINE: LINE created by NHN Japan in 2011 is the most popular social networking app in Japan and Taiwan. It is a proprietary instant messaging application for hand-held devices and PCs. LINE users can send their images, video, audio media messages to their friends who can view one another's profiles and make free VoIP calls. Throughout the world, LINE has 100 million users and 400 thousands active users daily (Nay, 2013).

WeChat: WeChat (also known as Weixin) launched by Tencent China in 2011 was one of the most popular mobile 
social networking app in China. It is a mobile phone text and voice messaging communication service. WeChat provides multimedia communication flexibility with text messaging, voice recording and messaging, broadcast messaging, file sharing, video calls and location sharing. With the location-based social plug-ins feature, it also provides unique meet-and-greet features like "Look Around", "Shake It", and "Drift Bottle" to chat with and befriend with local and international WeChat users (strangers). As of January 2013, WeChat has 300 million users (WeChat, 2013).

\subsubsection{Video Teleconferencing Services}

Skype: Skype established by Estonian developers in 2003, one of the top 10 most popular social networking apps, is now owned by Microsoft Inc. It is a proprietary VoIP service which allows its users to communicate with peers through voice, video, and instant messaging. Unlike other VoIP services, Skype is a hybrid peer-to-peer system which was originally called Sky Peer-to-Peer. Skype is popular for its file transfer and videoconferencing services. Voice calls and videoconference calls including screen sharing between two people within the Skype service are free of charge. With premium charge, the users can make calls to landline phones and mobile phones, and also make group video calls (videoconference calls) with up to 10 people together (Skype, 2012).

Google+ Hangouts: Hangouts providing a video chat service with up to 9 people on Google+ was launched in 2011. In turn, only Google + users can join the Hangouts. Google + is a multilingual social networking and identity service owned by Google Inc. The Google+ mobile app became the most popular free application in the Apple App Store (Tsotsis, 2011). Google (2013) reported that Google+ has a total of 500 million users and 235 million monthly active users. Hangouts provides video chat services for users to chat and/or watch YouTube video clips together with a maximum of 10 people for free of charge. However, Google limited Hangouts features in few countries, such as China, Thailand, and Vietnam.

\section{Research Methodology}

\subsection{Sample}

Convenient purposeful sampling procedures were used. The students involved in this study were 55 students enrolled in one of the Speech and Debate courses at a vocational university in central Taiwan. The course was facilitated by the instructor. The instructor was familiar with the online social networking features. A primary criterion was that none of the courses should be running for the very first time. Majority of the students were also familiar with basic functions of the social networking apps, such as sending/receiving SMSs, uploading/downloading files, or posting messages through a social room. A range of different types of mobile apps were given to the students as an option to use for the class communication and interaction purposes, but with sufficient similarities between types for use. Students used with their confidence at their convenience. All students were studying on undergraduate courses in an area of arts. Students completed the questionnaires independently during regular timetabled, face-to-face class hours at beginning and at the end of semester. The students knew that the eMASE module access and survey participation were voluntary actions. The dataset includes senior undergraduate students.

\subsection{Research Instrument}

The two surveys were developed for this study. The first survey containing the expectation form of the questionnaire (Q1) included 22 response and close-ended questions covering 1) demographics, 2) computer experience, 3) mobile device ownership, 4) context of mobile apps, 5) frequency of interaction with key apps, 6) amount of friends on key apps, and 7) effectiveness of e-cooperative learning. The scale that measures students' perspectives of effectiveness of e-cooperative learning is divided into five subscales (16 items): positive interdependence, individual accountability, group processing, social skills, and face-to-face interaction. Responses are completed on a five-point Likert scale ranging from "definitely agree" to "definitely disagree". Items for frequency of interaction with key apps, participants were asked to respond on a 5-point Likert scale ranging from "very frequently" (100\%) to "never" $(0 \%)$. The questionnaire also included ticking boxes (eg. Male or female), multiple choice questions (e.g. where to access information). The researchers piloted the instrument with an English instructor and 5 students who were not participated in the study to ensure that the questions would be interpreted correctly and understood by the target sample. Feedback received helped modify and clarify some of the questions for the internal validity. The internal reliability of the Q1 in the present study was good; Cronbach's $\alpha=.80$.

The second survey containing the perception form of the questionnaire (Q2) and student course evaluation consisted of 35 closed-ended questions measuring students' experience in the course. First 22 items from the Q1 were repeated on the Q2. The items were presented in the same order on each questionnaire. The only change on Q2 was that the 
questions were changed into the past tense. In addition, the course evaluation focuses on the perceived usefulness of eMASE in the course ( 9 items), and satisfaction of mobile social networking apps (4 items). The scale that measures students' perspectives of usefulness of the course is divided into three subscales: usefulness, confidence, and motivation. The scale that measures students' satisfaction of the uses of mobile apps toward learning includes the uses of Facebook, LINE, WeChat, and Skype. The internal reliability of the Q2 along with the student course evaluation in the present study was good; Cronbach's $\alpha=.85$.

\subsection{Course: Group Projects}

The course, and a kind of social e-learning environment, can be described as follows. The course was taught on the university campus, using a mixture of weekly 2-hour face-to-face meetings and social e-learning module. Significant parts of the course involved students working in groups (group size of 5-6), using the social learning apps to connect with one another in between classes. The course required students to work together to complete a number of group projects within a semester. The group project goal was to enhance students to learn, research, and practice how to utilize various mobile apps working with others to scaffold their learning. The group projects also provided students with opportunities to recognize how to work with their fellow peers in an eMASE module.

\subsection{Procedure}

The study was implemented and completed in an 18-week semester. The first survey was administered in hard copy at the start of the course during regular face-to-face class sessions. During the second week of the semester, the students were introduced to the mobile apps, including Faccebook, LINE, WeChat, Google's Hangouts, SMS, YouTube, email and received an hour-long training session on how to use these apps. The reason for introducing a variety of apps was that students use mobile technology to access information and to interact or communicate with others, but not necessarily through the same application (Kim \& Ball, 2011). Therefore, during the training session, all students were asked to download the apps to their mobile devices and add their fellow peers to their friend list on their social networking apps. Then, all students were asked to send a welcome post, share a link, and send a private message through the apps of Facebook, LINE, WeChat, SMS, and email. In addition, all students were asked to experience a 3-minute video teleconference with Google's Hangouts service. A variety of course activities along with social media apps included in this study were described in Table 1.

Table 1: Social Constructive Learning Activities vs. Mobile Learning Techs

\begin{tabular}{|c|c|c|}
\hline Focus & Class activity & Example of mobile techs \\
\hline $\begin{array}{l}\text { Navigation and retrieval of learning } \\
\text { materials }\end{array}$ & Browse the Internet & $\begin{array}{l}\text { All possible search engines, e.g. } \\
\text { Bing, Google, or Yahoo }\end{array}$ \\
\hline $\begin{array}{l}\text { Problem solving and information } \\
\text { sharing }\end{array}$ & Post inquiries & $\begin{array}{l}\text { Email, SMS, Facebook, LINE, } \\
\text { WeChat, Skype }\end{array}$ \\
\hline Multimedia learning & $\begin{array}{l}\text { Make video or audio clips } \\
\text { Post images, videos, audios, or text }\end{array}$ & YouTube, Facebook \\
\hline Multiple representations & Watch videos with peers together & YouTube, Google + Hangouts \\
\hline $\begin{array}{l}\text { Communication via mobile techs } \\
\text { Collaborative social communication }\end{array}$ & $\begin{array}{l}\text { Exchange comments with others } \\
\text { Video teleconference }\end{array}$ & $\begin{array}{l}\text { Facebook, LINE, WeChat, } \\
\text { Skype, Google+ Hangouts }\end{array}$ \\
\hline
\end{tabular}

Two group projects were required to complete for midterm and final exam grades. The students were encouraged to work in groups, using eMASE module to interact within the groups and to post/share information to other groups with whom they had communicated with. The purpose of this feature was to encourage students to exchange information and share accomplishments anywhere and anytime. While preparing a preliminary project, the students exchanged communication on their preferred social networking apps, mostly Facebook, and LINE. The students also interacted with their instructors regularly through the apps. While preparing the final production, the students uploaded their group projects/rehearsal presentation videos on YouTube and watched and discussed their own YouTube clips together with their team members on Google's Hangouts together. They also posted the YouTube links on the Facebook page. The instructor posted her comments and shared some resources and compliments. Through the Hangouts, the team can make changes to their presentation, get live input from remote team members, or just simply chat and make compliments on each other. The final production of work submissions were required to present in the class during the midterm and final exam weeks. The second hard-copy survey was administered during normally timetabled, face-to-face class sessions. 


\subsection{Data Collection}

Data were collected from the students on two surveys. The students completed the expectation form of the questionnaire (Q1) at the start of the course for the first time survey, and the perception form of the questionnaire (Q2) and the final course evaluation at the end of the course for the second time survey. All of the participants understood that they were completing the questionnaires and evaluation voluntarily and independently. The printed questionnaires and evaluation were completed during timetabled face-to-face course hours. Data were obtained from the two forms of questionnaires and the course evaluation questionnaires. Descriptive analysis was performed. The paired t-test was implemented to assess whether students were satisfied with their e-cooperative learning and the course experience by comparing scores from two sets of questionnaires, expectation. If the scores from these two sets of the questionnaires were not different, then students' expectations were fulfilled and it could be concluded that students were satisfied with the course learning experience. To what degree students satisfied with the course experience, a descriptive analysis was applied to analyze the course evaluation scores. Paired t-test was also implemented to determine if there was any difference between Q1 and Q2.

\section{Results}

\subsection{Survey Responses}

A total of 57 students were enrolled in the course. At the start of the study, students were asked to complete the Q1. Of the 57 questionnaire that were distributed, 56 took the survey yielding a response rate of $98.2 \%$. At the end of the study, students were asked to complete the Q2 and the course evaluation questionnaires. Among them, 55 students completed and returned the survey, yielding an overall response rate of $96.5 \%$.

\subsection{Demographics}

The total number of respondents to the first survey was 56 (44 female, 12 male). Mean age was 21.7 years $(\mathrm{SD}=.05$ ). All the students $(100 \%)$ were full-time undergraduates. A majority $(79 \%)$ of the respondents had 3-4 years of Facebook experience $($ mean $=3.39, \mathrm{SD}=.11)$. One-third $(38 \%)$ of them reported that they had $1-2$ year of LINE experience (mean $=.99, \mathrm{SD}=.12)$. Almost everyone $(98 \%)$ of them reported that they had less than a year of WeChat (mean=.64, $\mathrm{SD}=.04$ ) and Hangouts experience (mean $=.41, \mathrm{SD}=.00)$ prior to the class. Most $(81.8 \%)$ of the respondents reported that they used smart phones to access data while only a few students accessed data through their iPod touch (7\%) and others (2\%). The most popular place where students used mobile apps was home, with $75 \%$ accessing data frequently. Many $(76 \%)$ of the respondents also reported that they used mobile apps outside classroom at campus frequently. Similarly, more than half (69\%) of the respondents reported that they used mobile apps for commuting to and from school. The least popular place was shopping stores or restaurants.

Among the key applications, respondents had more friends on Facebook (mean= 503.78, SD $=57.49$ ) than LINE $($ mean $=53.91, \mathrm{SD}=7.75)$, WeChat $(\mathrm{mean}=35.11, \mathrm{SD}=8.45)$ and Hangouts (mean= .70). Facebook was used frequently by most the students $(95 \%)$. More than half of the respondents $(60 \%)$ used LINE frequently. WeChat (14\%) and Skype (27\%) were the least used by the respondents. Demographics characteristics in the second survey were similar to the first survey. A slight difference was more friends added to their friend list on the apps of WeChat (mean $=78.50)$ and Hangouts (mean= 18.01), and higher frequency of using Facebook $(98 \%)$ and LINE (69\%).

\section{3 e-Cooperative Learning of eMASE Module}

Response to research question 1: What are the impacts on e-cooperative learning using eMASE module? The patterning of students' experience in this study was then interpreted as shown as Figure 1. To answer research question 1, the main sources of data is the set of 16 Likert items concerning e-cooperative learning elements in the instrument. These are found in the data, though differing degrees.

A total of 56 students completed the Q1 at the beginning of the course. Students expected the environment of the course to be mobile assisted cooperative learning environment (mean=3.49, $\mathrm{SD}=.40$ ). Students had the highest expectation on the subscale of positive interdependence $(\mathrm{m}=4.32, \mathrm{SD}=.42)$ and the lowest on the subscale of face-to-face interaction (mean $=1.20, \mathrm{SD}=.42$ ). 


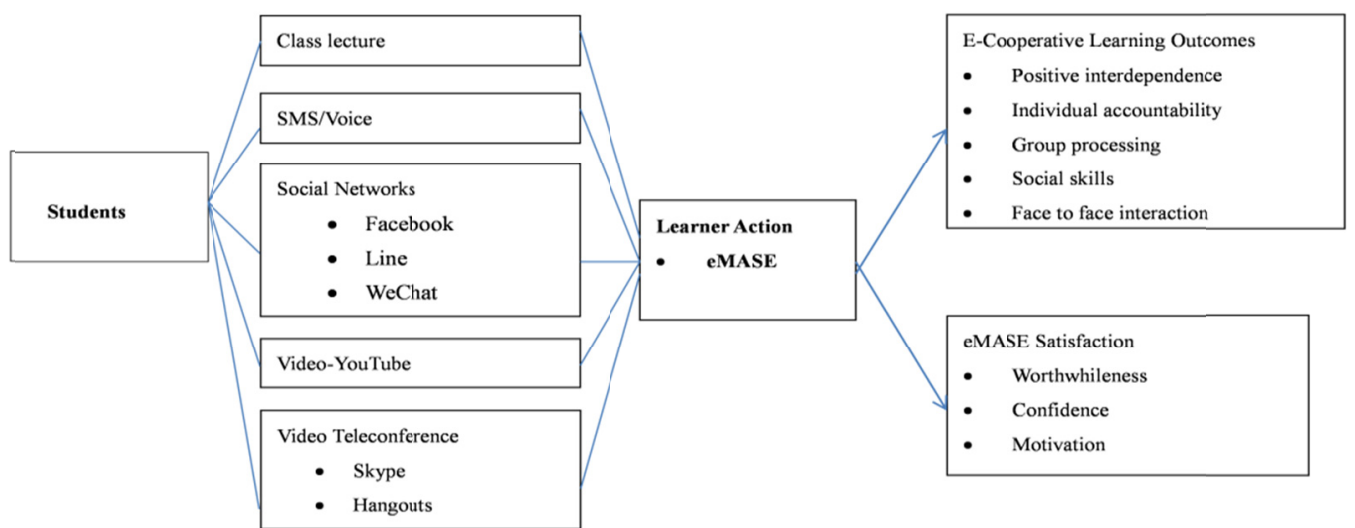

Figure 1: eMASE Module

A total of 55 students completed the Q2. The results showed that students experienced the learning environment of the course as eMASE module with a mean score of $3.34(\mathrm{SD}=.31)$. Perception questionnaire scores on all subscales were rated in the same way as student's expectation scores that students rated the highest on the subscale of positive interdependence (mean $=4.72, \mathrm{SD}=.39$ ) and the lowest on the subscale of face-to-face interaction (mean=1.17, $\mathrm{SD}=.43$ ). Two sets of questionnaire scores were compared using the paired $t$-test and no significant difference was found (Table 2). The results indicated that students' expectation was fulfilled and students were satisfied with the cooperative learning experiences.

Table 2: Comparison Scores between Q1 and Q2 Scores across e-Cooperative Learning Elements $(\mathrm{N}=55)$

\begin{tabular}{lcccc}
\hline Subscales of Cooperative Learning & $\begin{array}{c}\text { Number } \\
\text { of items }\end{array}$ & $\begin{array}{c}\text { Q1 Score } \\
\text { Mean (SD) }\end{array}$ & $\begin{array}{c}\text { Q2 Score } \\
\text { Mean (SD) }\end{array}$ & $\boldsymbol{p}$ \\
\hline Positive Interdependence & 4 & $4.32(.42)$ & $4.72(.39)$ & .376 \\
Individual Accountability & 3 & $4.28(.56)$ & $3.65(.61)$ & .384 \\
Group Processing & 3 & $3.82(.58)$ & $3.64(.71)$ & .196 \\
Social Skills & 3 & $3.81(.41)$ & $3.51(.71)$ & .301 \\
Face-to-Face Interaction & 3 & $1.20(.42)$ & $1.17(.43)$ & .170 \\
\hline TOTAL & 16 & $3.49(.40)$ & $3.34(.30)$ & .195 \\
\hline
\end{tabular}

Learning takes place when a task or a group goal is completed clear (Wang, et al., 2010). In turn, group members could benefit by acknowledging their efforts were part of group contribution toward their group goals. An analysis of the data indicated that a majority of the respondents (94\%) truly believed that efforts benefited their group toward to the group project. The most marked feeling was that almost every of the learners (93\%) described that they were glad to learn to use their mobile devices to access social networking apps as their new learning approach that appears powerful cooperation capabilities.

Element 1 Positive Interdependence: A majority of the respondents (95\%) truly believed that their efforts helped their group previous achieve their group goals on their projects. This finding was consistent with a previous study (Johnson \& Johnson, 1989) that found that the success of one learner is dependent on the success of the other learners.

Element 2 Individual Accountability: A majority of the respondents (91\%) reported that they assessed themselves and gave feedback, which benefited others by being able to see where improvement was needed. In addition, more than half (64\%) agreed that they received support and encouragement through the mobile apps in completing the group projects. This finding was consistent with a previous study (Johnson \& Johnson, 1994) that has found that having interaction with the peers, the learners can speed up their learning.

Element 3 Group Processing: Most (81\%) of the respondents believed they maintained a well working relationship. Similarly, more than half of the respondents $(60 \%)$ believe they were effectively achieving their common goals through the use of mobile apps. Therefore, by group processing, students were encouraged to work toward their group goals (85\%). This finding was consistent with previous studies (Ally, 2009; Kukulska-Hulme, 2010; Traxler, 2009) that have found that mobile techs help students actively share information.

Element 4- Social Skills: A majority (93\%) of the respondents indicated that this learning experience helped them 
learn how to effectively work with diversity via trust-building, communication. Two-third (62\%) of the respondents reported that communicating through mobile apps helped them solve the conflicts with their fellow peers. This finding corresponded to conclusion by other researcher (Koh, 2012) that high sociability encouraged more communication and encouraged group members to discuss the task at hand. More importantly, as Deb (2012) claims that mobile techs provide more interactive and communicative interaction between human and human. Mobile techs also extend the learning from inside the classroom to outside the classroom (Lan et al., 2007). In this study, with the mobile apps, group members obtained an opportunity to support each, communicate, and know each other. This finding supported the results of previous studies (Kreijns, Kirschner, Jochems, \& van Buuren, 2007) that social interaction has been shown to be an important dimension in computer-mediated learning.

Element 5 Face-to-Face Interaction: Although using social networking apps did helped student in learning, most $(92 \%)$ of them still felt that face-to-face interaction promoted each other's success. In this part, students did real work together, sharing information, supporting, and complementing each other's efforts to learn. The results support a previous study (Johnson \& Johnson, 1994) that claimed that "cooperative learning fosters exercises that require students to talk and listen, to write, to read, and to reflect on what is being studied rather than listen passively to a lecture" (p. 20).

Essentially, cooperative learning represents a learning environment evolved a student-centered learning approach in small group. Overall, the students indicated that they were able to cooperate with each other. With the clear goals they have in mind, they were able to help each other to complete the project and reach their goals together. Thanks to a variety of innovative mobile technologies, the teaching approach integrated with mobile apps created excellent opportunities for students to engage in more meaningful learning with the help of their group members. In summary, there was no relationship between demographic variables and all five elements of e-cooperative learning.

\subsection{Effectiveness of eMASE Module}

Response to research question 2: What are the students' attitudes toward learning using eMASE module? At the end of the course, the students were asked to provide evaluation about the course. Students in general had positive beliefs about the appropriateness of the use of eMASE module and a relatively strong interest in the use of eMASE on their course. Mean student evaluation scores about the course were high (Table 3). The main source of data in this section is the student course evaluation questionnaire containing 13 Likert items. Prior to analysis, 5 items of usefulness, 2 items of confidence, 2 items of motivation, and 4 items of satisfaction toward the mobile apps were calculated for mean scores and standard deviation as illustrated in Table 3.

Table 3: Mean, Standard Deviation, and Number of Items in Each Subscale

\begin{tabular}{|c|c|c|c|}
\hline Sub-Scales & Number of items & Mean & Standard Deviation \\
\hline Usefulness & 5 & 3.84 & .75 \\
\hline Confidence & 2 & 4.27 & .91 \\
\hline Motivation & 2 & 3.66 & .85 \\
\hline Satisfaction & 4 & 3.20 & 1.29 \\
\hline (1) Facebook & & 4.83 & .70 \\
\hline (2) LINE & & 3.26 & 1.52 \\
\hline (3) WeChat & & 2.34 & 1.52 \\
\hline (4) Hangouts & & 2.36 & 1.43 \\
\hline
\end{tabular}

Usefulness: A majority (81\%) of the respondents reported that they felt this experience on this course was useful. Similarly, they (77\%) enjoyed using the mobile apps as an integral part of their learning activities. Many (77\%) of the respondents agreed that the mobile social networking apps helped them learn. This result was consistent with a previous study (Deb, 2012) that mobile technology helps students reach their learning goals.

Confidence: Results revealed that usefulness with the use of mobile social networking apps was perceived as the highest score (mean=4.27). Many of the respondents $(89 \%)$ agreed that they felt confident using the mobile apps on this course and they $(87 \%)$ felt confident to take another course using mobile apps like this in the future.

Motivation: Overall motivation with the course was also perceived as positive (mean $=3.66, \mathrm{SD}=.85$ ). Majority $(81 \%)$ of the respondents agreed that they felt using the mobile apps on this course really worthwhile. More than half of the respondents (64\%) reported that they felt being motivated from interacting with their instructor on the mobile apps. The students have interaction with their instructor as a facilitator providing encouragement or help when needed. This finding was consistent with the findings of recent studies (Effandi \& Zanaton, 2007; Kan 2011) that the more the facilitators appeared online interacting with students and participating in discussions, the mores students 
were encouraged and motivated.

Satisfaction: The students were asked to rate their satisfaction on the mobile social networking apps, including Facebook, LINE, WeChat, and Google+ Hangouts. The overall mean score of students satisfaction toward the use of different apps was $3.20(\mathrm{SD}=1.10)$ with the highest score on Facebook (mean=4.83) and was followed closely by LINE with mean score of 3.26 . A total of $94.3 \%$ of the respondents strongly agree that they were very satisfied using Facebook for their projects. Overall, the results from the course evaluation questionnaires reported that students were satisfied very much using the mobile social networking apps for their group projects. One interpretation of this data is that students will use the tools they are familiar with and meet their needs (Clough, Jones, McAndrew, \& Scanlon, 2009). Therefore, when the students become comfortable with mobile and social media, it is likely they will use them for their learning needs. Not surprisingly, only few $(21 \%)$ agreed that they were satisfied using Google+ Hangouts for doing group projects. Only very few (7\%) indicated that they have experiences in using Google+ Hangout prior this course. Part of the explanation for that may be the location where the students lived. Most of the students in this study lived around the campus. That is, students, in general, found it more convenient to discuss group projects face-to-face rather than video teleconference. Instead meeting via the Hangouts app, they could choose to meet face-to-face for the group assignments or oral presentation rehearsals.

To examine the relationships between the means of subscale of effectiveness of eMASE module and demographic variables, Pearson's $r$ correlation coefficient was used. No significant relationship was founded between the frequency of app usage and the satisfaction of the use of apps. Interestingly, students who were satisfied with Facebook use were more likely to be satisfied with LINE for completing their group projects (Pearson's $\mathrm{r}=.354$; $p<.01$ ). A moderate positive significant correlation was noted between the amount of friends on Facebook friend list and confidence of using eMASE toward learning (Pearson's $r=.394, p<.05$ ). The finding indicated that students who have more friends on their Facebook friend list rated them more highly confident than students who have less.

\section{Discussions}

The eMASE module was developed to the course in this study to create an effective e-cooperative learning environment based on social constructivist theory. For the purpose of enhancing collaboration, eMASE module was implemented in a course. Results of the present study suggest that that the mobile social networked learning promotes cooperative learning among the students and enhances interactions with others. Learning is a social activity (Vygotsky, 1978) and interaction is the primary element in social activity as the process of learning (Woo \& Reeves, 2008). The true alternative for foster interaction with others in the class is a small class lecture. Unfortunately, this alternative in most cases in Taiwan is financially infeasible. Therefore, collaborative online small group provides some possibilities as Borovik (2011) and Libert (2010) suggest that linking online social networking sites through a hand-held device provides an avenue for small group interaction at anywhere and anytime. This learning module supported students collaboration as the students rated positive feelings for all of the five elements of cooperative learning (mean= $3.34 \mathrm{SD}=.62$ ). The researchers agreed that computer technology could bring about changes in the teacher's role from a knowledge-provider to students' guide in their search for knowledge, and from a classroom lecturer to a coursework designer. The setting of learning networks and environments has become far more important. Teachers need to know more than course content; design issues now has become essential.

The course was designed to include group projects and many peer interactions through the use of mobile social networking apps. Social media apps gave learners the capability to access the Internet and enhance communication with other people. The social communication of these technologies could embed new ways for collaborating (Koh \& Lim, 2012). Students had to discuss group assignments of this learning environment, the combination of physical and digital learning environment. This finding was consistent with previous studies (Chen \& Bryer, 2012; Smith \& MacGregor, 1992; Vygotsky, 1978) that claimed that most learning occurs through social interaction. It was essential for the instructor as a facilitator finding ways to encourage and engage students in the learning process (Bauersfeld, 1995; Maor, 2003). The more the teacher interacted with students, the more students were encouraged to engage to learn (Sthapornnanon, Sakulbumrungsil, Theeraroungchaisri, \& Watcharadamrongkun, 2009) as student engagement in the learning process was important for learning (Zerihun, Beishuizen, \& Os, 2012). This was consistent with the results of the course evaluation that students were satisfied with the use of mobile networking apps toward their learning. The analysis of evaluation questionnaires revealed that students agreed that their learning was enhanced and they were satisfied with the course.

From this study, a pattern emerged of mobile social networking apps users as more confident students are typically engaged in their learning. Whether higher frequency of using mobile networking apps increases student's confidence 
is unclear from the data. To determine the direction of the relationship between e-cooperative learning and the use of social networking apps, experimental studies could be developed. More research needs to be done to inform educators about the effects of mobile learning on student achievement. In the meantime, the finding highlights the value of mobile techs on teaching and learning. It might be a resource for anyone considering making use of Web 3.0 technologies in teaching or learning.

\subsection{Conclusions}

In conclusion, mobile social networking apps have proved to be a technology valued by students. This study aimed to see whether there were significant differences between students' expectations about e-cooperative learning with mobile social networking apps, at the start of a course, and what they had to say about their experiences of eMASE module, at the end of a course. In addition, this study determined whether students were satisfied with the use of mobile social networking apps toward to their learning from the student course evaluation questionnaires. The dataset was from 55 undergraduate students taking one of the courses, set in the arts to obtain answers to the research questions. The course was developed, designed, and implemented with the use of social networked learning based on social constructivism theory. Various group projects and activities were included for students to generate, communicate, and collaborate their learning, and constructed their new learning in a course. Overall, the analyses of the results indicated that the students benefited from working in an e-cooperative environment along with the assistance from the using of mobile apps. Their uses of mobile apps were limited to a few familiar apps, such as Facebook and LINE. However, overall, they really enjoyed themselves while using eMASE module throughout this course and the entire learning experience in the course was perceived as useful to their learning. From the results, it can be seen that the students were actively participating in their learning process individually and also as part of learning community. It enabled students to instantly engage with friends across chat platforms including Facebook, LINE, or Hangouts. Additionally, the findings suggest that students were in control of their use of mobile apps working on their learning activities without teacher's directions. These students whether or not using mobile apps frequently or rarely outside the classroom were in fact supporting and continuing their classroom learning. Apart from learning, they also developed their skills and confidence in the usage of multimedia and Web apps which is one of the important elements in this rapid developing country.

This course promoted a social constructivist learning environment in which students perceived that new knowledge was constructed and reported that they were satisfied with the course. This study is useful in showing that these undergraduate students had positive feelings about mobile networking learning. It is also useful in showing that there are possibilities to implement wireless and mobile education in higher education settings and there are no good reasons to suspect that social networking apps are the tools distract students from learning. The synergy between mobile education and cooperative learning holds enormous potentials.

\section{References}

Ajjan, H., \& Hartshorne, R. (2008). Investigating faculty decisions to adopt Web 2.0 technologies: Theory and empirical tests. Internet and Higher Education, 11, 71-80. http://dx.doi.org/10.1016/j.iheduc.2008.05.002

Ally, M. (2009). Introduction. In M. Ally (Ed.), Mobile Learning: Transforming the Delivery of Education and Training (pp. 1-6). Edmonton, AB: AU Press.

Bauersfeld, H. (1995). The structuring of structures: Development and function of mathematizing as a social practice. In L. R. Stegge \& J. Gales (Eds.), Constructivism in Education(pp. 137-158). Hillsdale, NJ: Erlbaum.

Borovik, A. (2011). Information technology in university? Level mathematics teaching and learning: A mathematician's point of view. Research in Learning Technology, 19(2), 73-85. http://dx.doi.org/10.1080/09687769.2010.548504

Bruner, J. (1987). Prologue to the English Edition. In R. W. Rieber and A. S. Carton (Eds.), The Collected Works of L. S. Vygotsky, Volume 1, Problems of General Psychology. New York, NY: Plenum Press.

Chen, B., \& Bryer, T. (2012). Investigating instructional strategies for using social media in formal and informal learning. International Review of Research in Open \& Distance Learning, 13(1), 87-104.

Cheung, C. M. K., Chiu, P. Y., \& Lee, M. K. O. (2011). Online social networks: Why do students use Facebook? Computers in Human Behavior, 27, 1337-1343. http://dx.doi.org/10.1016/j.chb.2010.07.028

Clough, G., Jones, A., McAndrew, P., \& Scanlon, E. (2009). Informal learning evidence in online communities of mobile device enthusiasts. In M. Ally (Ed.), Mobile Learning: Transforming the Delivery of Education and 
Training (pp. 25-44). Edmonton, AB: Alberta UP.

Deb, S. (2012). Distance learning in developing countries through multimedia technology using mobile devices. International Journal of Education and Learning, 1(1), 41-48.

Doolittle, P.E., \& Hicks, D. (2003). Constructivism as a theoretical foundation for the use of technology in social studies. Theory and Research in Social Education, 31(1), 72-104. http://dx.doi.org/10.1080/00933104.2003.10473216

Effandi, Z., \& Zanaton, I. (2007). Promoting cooperative learning in science and mathematics education: A Malaysia perspective. Eurasia Journal of Mathematics, Science \& Technology Education, 3(1), 35-39.

Facebook (2013). Number of mobile active Facebook users. Statista. Retrieved from http://www.statista.com/statistics/223264/number-of-mobile-active-facebook-users/

Ford, N., Bowden, M., \& Beard, J. (2011). Learning together: using social media to foster collaboration in higher education. In L. A Wankel and C. Wankel (Eds.), Higher Education Administration with Social Media: Cutting-edge Technologies in Higher Education, Volume 2, (pp. 105-126). Bingley, UK: Emerald. http://dx.doi.org/10.1108/S2044-9968(2011)0000002009

Godwin-Jones, R. (2008). Emerging technologies mobile e-computing trends: Lighter, faster, smarter. Language Learning \& Technology, 12(3), 3-9.

Google (2013). Retrieved from www.google.com/about

Grodecka, K., Wild, F., \& Kieslinger, B. (2009). How to use social software in higher education. iCamp Handbook. Retrieved from http://www.icamp.eu/wp-content/uploads/2009/01/icamp-handbook-web.pdf

Hlodan, O. (2010). Mobile Learning Anytime, Anywhere. In J. Attewell \& C. Savill-Smith, (Eds.), BioScience, 60(9), 682-682. Retrieved from http://caliber.ucpress.net/doi/abs/10.1525/bio.2010.60.9.4

Johnson, D. W., \& Johnson, R. T. (1975). Learning Together and Alone, Cooperation, Competition, and Individualization. Englewood Cliffs, NJ: Prentice-Hall.

Johnson, D. W., \& Johnson, R. T. (1989). Cooperative and competition: Theory and research. Edina, MN: Interaction.

Johnson, D. W., \& Johnson, R. T. (1994). Joining Together: Group theory and group skills (5th Ed.). Boston, MA: Allyn \& Bacon.

Kan, S. O. (2011). Cooperative learning environment with Web 2.0 tool e-portfolios. European Journal of Social Sciences, 21(1), 17-27.

Keskin, N. O., \& Metcalf, D. (2011). The current perspectives, theories and practices of mobile learning. The Turkish Online Journal of Educational Technology, 10(2), 202-208.

Kim, B., \& Ball, M. (2011). Mobile use in medicine: Taking a cue from specialized resources and devices. Reference Librarian, 52(1/2), 57-67.

Koh, E., \& Lim, J. (2012). Using online collaboration applications for group assignments: The interplay between design and human characteristics. Computers \& Education, 59, 481-496. http://dx.doi.org/10.1016/j.compedu.2012.02.002

Kreijns, K., Kirschner, P., Jochems, W., \& van Buuren, H. (2007). Measuring perceived sociability of computer-supported collaborative learning environment. Computers \& Education, 49(2), 176-192. http://dx.doi.org/10.1016/j.compedu.2005.05.004

Kukulska-Hulme, A. (2010). Mobile learning as a catalyst for change. Open Learning, 25(3), 181-185. http://dx.doi.org/10.1080/02680513.2010.511945

Lan, Y., Sung, Y., \& Chang, K. (2007). A mobile-device-supported peer-assisted learning system for collaborative early EFL reading. Language Learning \& Technology, 11(3), 130-151.

Libert, B. (2010). Social Nation: How to Harness the Power of Social Media to Attract Customers, Motivate Employees, and Grow Your Business. Hoboken, NJ: Wiley.

Looi, C., Seow, P., Zhang, B., So, H., Chen, W., \& Wong, L. (2010). Leveraging mobile technology for sustainable seamless learning: A research agenda. British Journal of Educational Technology, 41(2), 154-169. http://dx.doi.org/10.1111/j.1467-8535.2008.00912.x 
Maor, D. (2003). The teacher's role in developing interaction and reflection in an online learning community. Edu Media Int., 40, 127-137. http://dx.doi.org/10.1080/0952398032000092170

Mayer, R.E. (2001). Multimedia Learning. Cambridge, UK: Cambridge UP. http://dx.doi.org/10.1017/CBO9781139164603

McGarr, O. (2009). A review of podcasting in higher education: Its influence on the traditional lecture. Australasian Journal of Educational Technology, 25(3), 309-321.

MoLeNET (2007). What is mobile learning? Retrieved from http://www.molenet.org.uk/

Nay, J. (2013, January 19). Line VoIP and messaging app now has more than 100 million users. Retrieved from http://www.trutower.com/2013/01/19/line-voip-and-im-app-now-has-more-than-100-million-users/

Schreiber, B.E., Fukuta, J., \& Gordon, F. (2010). Live lecture versus video podcasting in undergraduate medical education: A randomized controlled trail. BMC Medical Education, 10(1), 68. http://dx.doi.org/10.1186/1472-6920-10-68

Skype (2012). Group video calls. Retrieved from http://www.skype.com/en/features/group-video-chat/

Smith, B. L., \& MacGregor, J. T. (1992). What is collaborative learning? In Collaborative Learning: A Sourcebook for Higher Education. National Center on Postsecondary Teaching, Learning, \& Assessment. Syracuse, NY: Syracuse U.

Spriensma, G. J. (2012). Social Networking Apps. Utrecht, Netherlands: Distimo.

Sthapornnanon, N., Sakulbumrungsil, R., Theeraroungchaisri, A., \& Watcharadamrongkun, S. (2009). Instructional design and assessment: Social constructivist learning environment in an online professional practice course. American Journal of Pharmaceutical Education, 73(1), 1-9. http://dx.doi.org/10.5688/aj730110

Traxler, J. (2009). Current state of mobile learning. In M. Ally (Ed.), Mobile Learning Transforming the Delivery of Education and Training (pp. 9-24). Athabasca, AB: Athabasca UP.

Tsay, M., \& Brady, M. (2010). A case study of cooperative learning and communication pedagogy: Does working in teams make a difference? Journal of the Scholarship of Teaching and Learning, 10(2), 78-89.

Tsotsis, A. (2011). Google+ now the top free app in the Apple App Store Retrieved TechCrunch from http://techcrunch.com/2011/07/20/google-now-the-top-free-app-in-the-apple-app-store/?utm_source=feedburner \&utm_medium $=$ feed\&utm_campaign=Feed $\% 3 \mathrm{~A}+$ Techcrunch $+\% 28$ TechCrunch $\% 29$

Ullich, C. et al. (2008). Why Web 2.0 is good for learning and for research: Principles and prototypes WWW 2008. April 21-25, Beijing, China.

Vygotsky, L. S. (1978). Mind in Society. Cambridge, MA: Harvard UP.

Walton, A., Weller, M., \& Conole, G. (2008). Social: Learn- widening participation and sustainability of higher education. Proceedings EDEN 2008: Annual Conference of the European Distance and E-Learning Network, June 2008, Lisbon, Portugal.

Wang, J., Lin, C., Yu, W., \& Wu, E. (2012). Meaningful engagement in Facebook learning environments: Merging social and academic lives. Turkish Online Journal of Distance Education, 14(1), 302-322.

Wang, J., Wang, C.H., Fang, Y.C., \& Lin, C. C. (2010). Benefits of Web 2.0 in the college writing classroom. The International Journal of Learning, 17(2), 439-450.

WeChat (2013). Sharing content via WeChat Retrieved from http://dev.wechat.com/intro/

Woo, Y., \& Reeves, T. (2008). Interaction in asynchronous Web-based learning environments: Strategies supported by educational research. Journal of Asynchronous Learning Networks, 12(3), 179-194.

Zerihun, Z., Beishuizen, J., \& Os, W. V. (2012). Student learning experience as indicator of teaching quality. Educational Assessment, Evaluation and Accountability, 24(2), 99-111. http://dx.doi.org/10.1007/s11092-011-9140-4 